\title{
Strategies for modulating the inflammatory response after decompression from abdominal compartment syndrome
}

\author{
Shinil K Shah ${ }^{1,2,3}$, Fernando Jimenez, ${ }^{1}$, Phillip A Letourneau², Peter A Walker ${ }^{1,2}$, Stacey D Moore-Olufemi ${ }^{1,3}$, \\ Randolph H Stewart ${ }^{3}$, Glen A Laine ${ }^{3}$ and Charles S Cox Jr1,3,4*
}

\begin{abstract}
Background: Management of the open abdomen is an increasingly common part of surgical practice. The purpose of this review is to examine the scientific background for the use of temporary abdominal closure (TAC) in the open abdomen as a way to modulate the local and systemic inflammatory response, with an emphasis on decompression after abdominal compartment syndrome (ACS).

Methods: A review of the relevant English language literature was conducted. Priority was placed on articles published within the last 5 years.

Results/Conclusion: Recent data from our group and others have begun to lay the foundation for the concept of TAC as a method to modulate the local and/or systemic inflammatory response in patients with an open abdomen resulting from ACS.
\end{abstract}

Keywords: Compartment syndromes, Decompression, Laparotomy, Systemic inflammatory response syndrome, Negative pressure dressings

\section{Introduction}

Management of the open abdomen is an increasingly common part of modern surgical practice. Common clinical situations that mandate the use of temporary abdominal closure (TAC) include intra-abdominal hypertension (IAH) with new organ dysfunction (abdominal compartment syndrome (ACS)), intraabdominal sepsis without adequate source control, damage control in trauma, and mesenteric ischemia [1]. While it is difficult to estimate the prevalence or economic impact of the open abdomen, it is associated with significant issues contributing to morbidity and mortality, including development of ventral hernias, enteroatmospheric fistulas, and un-intentional protein loss [2].

The focus of this review is to detail current thoughts on the use of TAC in the management of the open

\footnotetext{
* Correspondence: charles.s.cox@uth.tmc.edu

'Department of Pediatric Surgery, University of Texas Medical School at

Houston, Houston, Texas, USA

Full list of author information is available at the end of the article
}

abdomen, with particular attention to decompression after ACS. We review the relevant intra-abdominal related pathophysiology involved with ACS (with emphasis on the gut), the different types of TAC and evidence to support various choices. Recent data from our group and others have begun to lay the foundation for the concept of TAC as a method to modulate the local and/or systemic inflammatory response after ACS.

\section{Abdominal compartment syndrome}

As defined by the International Conference of Experts on Intra-abdominal Hypertension and Abdominal Compartment Syndrome (World Society of the Abdominal Compartment Syndrome, http://www.wsacs.org), ACS is defined as IAH (increased intra-abdominal pressure (IAP) (> $20 \mathrm{mmHg})$ ) leading to new organ dysfunction/ failure $[3,4]$. In general, there is improvement in organ function after decompressive laparotomy. ACS can be subdivided into primary, secondary and recurrent types, depending on whether the inciting factors are abdominopelvic (primary) or in a setting free of intra- 
abdominal injury (secondary) [4]. Key factors in the development of primary ACS include continued hemorrhage and hemorrhagic shock from trauma, decreased space secondary to abdominal packing and bleeding, tissue edema, and translocation of fluid (third spacing) [3]. Secondary ACS is more common in settings of systemic injury (i.e., burns and or sepsis) in the setting of massive fluid resuscitation [4]. The cornerstone of management of ACS involves early decompressive laparotomy [5], but mortality from ACS remains high, especially when the diagnosis is delayed [6].

\section{Intra-abdominal pathophysiology involved with abdominal compartment syndrome/open abdomen: major etiological factors}

Pathophysiology relevant to a discussion of TAC after ACS can be divided into several general processes including global and regional ischemia/reperfusion (IR), intestinal edema, translocation of fluid into the lumen and peritoneal cavity (third spacing), systemic neutrophil priming, and reperfusion related injury after abdominal decompression.

\section{Intestinal ischemia/reperfusion}

Hemorrhagic shock followed by resuscitation leads to intestinal injury by IR related mechanisms. The gut is especially susceptible to shock related reductions in blood flow secondary to both reductions in circulating blood flow as well as shock related redistribution in blood flow. Laboratory based studies have determined that the kidney, stomach, and intestines experience the greatest decrease in blood flow after hemorrhagic shock [7]. Ischemic injury in the intestine continues to persist after crystalloid based resuscitation [8].

The pathophysiology related to IR mediated gut injury is similar to that affecting the lungs and kidneys; it has been termed by some investigators as the acute intestinal distress syndrome [9]. IR results in mucosal damage and increased permeability. Mucosal damage has been attributed to numerous factors including intestinal phospholipase A2 (PLA 2) mediated arachadonic acid derived byproducts [10], mast cell infiltration and degranulation [11], epithelial cell apoptosis [12], increases in platelet activating factor (PAF) and pro-inflammatory cytokines [13], free radical mediated injury [14], and production of endothelins [15]. Consequences of these interacting factors include intestinal edema.

The increase in mucosal permeability induced by gut IR may account, in part, for distant organ injury. A large body of literature has focused on lung injury. IR mediated lung injury may represent a neutrophil mediated event. Gut derived endotoxin escape into the systemic circulation has also been implicated, potentially through a TNF- $\alpha$ related mechanism [16]. Other proinflammatory cytokines (e.g., IL-1 $\alpha$, IL-1 1 , IL-6, IL-8,
IL-18, cytokine-induced neutrophil chemoattractant, and granulocyte colony stimulating factor (G-CSF)) have also been investigated as contributors, potentially by upregulating endothelial based participants in neutrophil adhesion, such as E-selectin or intracellular adhesion molecule-1 (ICAM-1) [17-20]. Membrane derived phospholipids such as PAF, have also been implicated [21], and may be involved in priming of naïve neutrophils. Investigators have also noted PLA 2 mediated arachidonic acid byproducts to participate in IR mediated lung injury [22]. Other potential mediators of distant lung injury include toll like receptors [23], oxygen derived free radicals [24], activation of alveolar macrophages [24], nitric oxide [25], activation of nuclear factor $-\kappa \mathrm{B}$ [26], activation of complement [27], and production of endothelins [28]. Mesenteric lymph may represent the major conduit for gut derived mediators of distant organ injury, as will be described later in this review.

IR injury leads to inflammatory cell infiltration into the intestinal muscularis and is associated with activation of transcription factors such as nuclear factor $-\kappa \mathrm{B}$, signal transduction and activator of transcription - 3 (STAT-3), and nitric oxide, and leads to ileus i $[29,30]$. Ileus leads to significant consequences, including delaying enteral feeding and increasing the risk of septic complications, hospital length of stay, and health care costs [31].

\section{Resuscitation strategies}

Resuscitative strategies may play a role in the development of secondary ACS and ACS in the open abdomen. In particular, high volume resuscitation (in the setting of previous IR injury) may increase risk of development of ACS, potentially via exacerbation of organ edema. Multiple reports have associated high volumes of crystalloids and/or high volume of blood products to harbor increased risk for developing IAH and/or ACS [32-36]. Colloid based resuscitative strategies have been associated with decreased incidence of ACS, secondary in part to decreasing total volume of fluids administered [34]. With the increased adoption of blood product based resuscitative strategies, it is important to recognize that administration of large amounts of blood products has also been associated with an increased risk of developing ACS.

\section{Abdominal effects of abdominal compartment syndrome/ open abdomen \\ Intestinal edema}

Aggressive resuscitative strategies and damage control surgical procedures alter hydrostatic and oncotic pressure differentials contributing to the formation of hydrostatic intestinal edema [33-39]. Specifically, the decrease in plasma oncotic pressures (secondary to hemodilution from resuscitation) combined with the increase in 
capillary hydrostatic pressures (secondary to abdominal (peri-hepatic) packing induced increases in mesenteric venous pressures) leads to net efflux of fluid into the interstitium. Contributing factors also include increased capillary permeability from IR mediated gut injury in the context of hemorrhagic shock/resuscitation [40-42], and elevated central venous pressures during resuscitation which prevents lymphatic mediated efflux of fluid out of the interstitium (secondary to an elevated central venous pressure to lymphatic flow gradient) $[43,44]$. The interplay of these variables is demonstrated in Figure 1.

Edema is often viewed as an inevitable consequence of resuscitation with little attention paid to its potential role as an initiator and/or propagator of dysfunctional signaling pathways. In laboratory models, intestinal edema (in the absence of neutrophil mediated injury or IR injury) serves to promote ileus, potentially by activation of signal transduction cascades (nuclear factor $-\kappa \mathrm{B}$ and STAT-3), decreased phosphorylation of the regulatory myosin light $\mathrm{chain}_{20}$, and decreased intestinal contractility [45]. Additionally, edema alters the physical properties of the intestine, including changes in calponin, vimentin, and filamentous:globular actin, increases in interstitial pressure, and decreases in stress and residual stiffness [45]. Certain therapies that lead to improved intestinal transit (e.g., hypertonic saline) reverse physical changes induced by edema $[45,46]$. In addition, edema contributes to increased tissue permeability [47].

In addition to edema causing ileus, there is some evidence that ileus may lead to a cycle preventing edema resolution, secondary to interference with lymphatic mediated efflux of interstitial fluid [3,48]. Because lymphatic vessels within the bowel wall are valve-less [49],

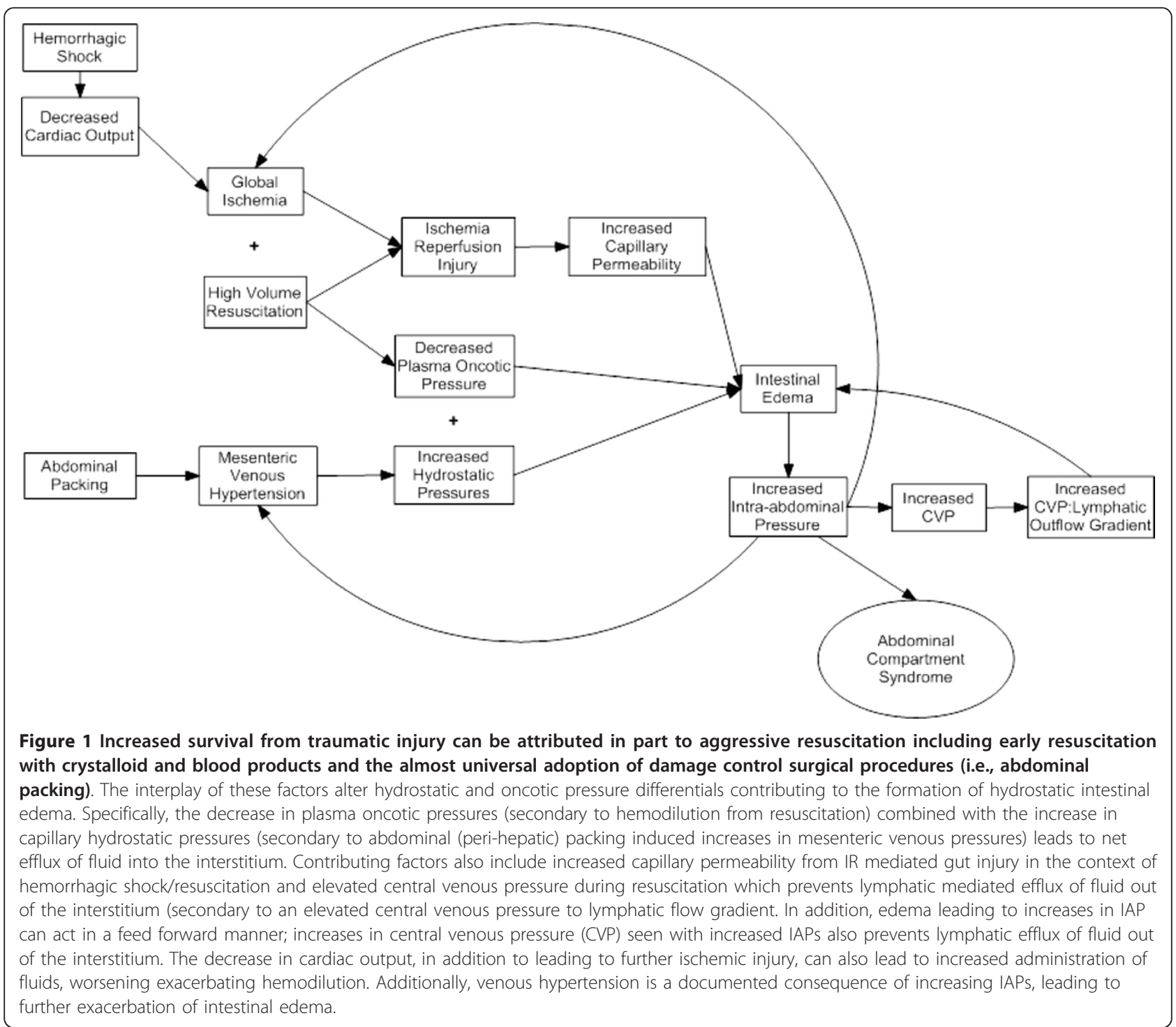


forward flow of interstitial fluid into lymphatic vessels is dependent on peristalsis. Therefore, decreased intestinal contractility may prevent efflux of excess interstitial fluid into lymphatic channels and subsequent amelioration of edema. Moore-Olufemi et al. examined the effects of primary and secondary ACS on mesenteric lymph flow and suggested that abdominal decompression may exert a beneficial effect on intestinal edema by decreasing lymphatic outflow pressures, and improving lymph mediated efflux of tissue water [50].

\section{The abdomen as an inflammatory bioreactor}

Mesenteric lymph Gut derived lymph has increasingly been studied as a medium for systemic neutrophil priming and activation leading to distant organ injury. Early studies indicated that mesenteric lymph sampled after hemorrhagic shock activated neutrophils and was toxic to endothelial cells [51]. Given the almost immediate delivery of mesenteric derived lymph to the lungs, interest grew evaluating mesenteric lymph as the responsible agent for shock/resuscitation induced lung injury. Subsequent studies confirmed these preliminary findings and also demonstrated that mesenteric lymph represented a priming agent for naïve neutrophils, increased $\mathrm{E}$ and P-selectin and ICAM-1 expression on endothelial cells, and contributed to pro-inflammatory cytokine production (IL-6) [52-56].

Further demonstrating this relationship, lymphatic diversion (usually by ligation) has been shown to prevent distant organ injury $[53,57]$. As this does not represent a translatable therapeutic strategy in most cases, other interventions have been studied as a way to modulate post IR mesenteric lymph bioactivity, including hypertonic saline $[52,58]$. In addition, the apparent role of leukotriene B4 in lymph mediated lung injury may offer new avenues for pharmacologic inhibition [59]. However, novel translatable ways to affect the proinflammatory status of mesenteric lymph may offer promise to attenuate distant organ injury.

Peritoneal fluid Factors contributing to ACS include translocation of gut derived interstitial fluid into the peritoneum. Peritoneal fluid, historically, has not been evaluated as a potential driver of systemic inflammation. Evidence from other investigators, however, indicates that peritoneal fluid may be biologically active and may represent a therapeutic target. Peritoneal fluid from burn patients contains increased levels of pro-inflammatory cytokines [60] and gut derived peritoneal fluid (accumulated during abdominal aortic aneurysm repair) increases polymorphonuclear cell expression of CD11b [61]. Increased concentrations of pro-inflammatory cytokines in peritoneal fluid has been shown to correlate with poorer outcome in burn patients with IAH/ACS [60] and in an animal model of peritonitis [62].
Peritoneal fluid and lymph are similar in that the source of both is interstitial fluid. In addition to uptake via lymphatic channels, gut derived interstitial fluid is redistributed into the gut lumen and the peritoneal cavity [63]. Adding to the potential relevance of peritoneal fluid as an initiator and/or propagator of systemic inflammation is the fact that peritoneal fluid is taken up into the systemic circulation via lymphatic (primarily) and capillary channels. This process is enhanced in the setting of inflammation [64]. Peritoneal drainage after cardiopulmonary bypass was associated with decreased serum levels of pro-inflammatory cytokines [65]. Shah et al. recently demonstrated that peritoneal fluid collected after development of ACS primes naïve neutrophils and monocytes via receptor dependent and independent pathways and that decompressive laparotomy does not significantly alter the priming capabilities of peritoneal fluid [66]. In addition, peritoneal fluid from a model of multiple organ dysfunction driven by gut IR and intraabdominal sepsis has also been shown to prime naïve neutrophils [67]. In addition to having a potentially bioactive role, a purely mechanical role has been suggested by certain studies. Catheter drainage of ascites may prevent the need for decompressive laparotomy in certain cases of ACS [68].

Reperfusion syndrome after abdominal decompression Decompressive laparotomy is widely accepted as a mandatory intervention in patients with ACS [5]. Although this procedure is associated with, often, immediate improvement in some measures of organ function, little attention is often paid to the fact that decompression may lead to release of inflammatory mediators that serve to propagate multiple organ dysfunction secondary to a reperfusion like injury $[69,70]$. Overt reperfusion syndrome resulting in death is rare; however, a postdecompression reperfusion syndrome is a potential reason why mortality from ACS remains high [6]. A central component of ACS associated reperfusion syndrome likely occurs secondary to repeated intestinal IR injury.

While most previously published animal models of ACS poorly mimic its pathogenesis [71], they are extremely useful for determining the effects of IAH, particularly in the development of intestinal ischemia. Development of ACS is associated with decreased intestinal perfusion, and these changes occur well before histological evidence of injury [72]. Decreased local perfusion persists even when global hemodynamic parameters remain within the normal range, indicating increased IAP as an inciting factor [73]. More recent work has begun to define the inflammatory response initiated by abdominal decompression. Rezende-Neto et al. demonstrated a significant increase in lung neutrophil myeloperoxidase, IL-6, and TNF- $\alpha$ after decompression from a period of ACS, suggesting decompression as 
an inciting event for injury [74]. This has been replicated in other investigations; Oda et al. demonstrated a similar exacerbation of cytokine levels and lung injury when evaluating a period of induced ACS after hemorrhagic shock/resuscitation induced injury, with levels and injury continuing after cessation of the period of ACS (i.e., decompression) [75]. Prior hemorrhagic shock/resuscitation induced injury results in a lower tolerance for increasing IAPs with regard to end organ injury [76]. Although ACS is not classically viewed as an initiator of intestinal IR injury, the data presented do serve to support this notion. Indeed, artificially induced ACS and subsequent decompression has been used as a model for the study of kidney IR injury and recently, to mimic intestinal IR injury [77,78]. Additionally, the published data on decompression leading to increased systemic neutrophil activation and continued bioactivity of peritoneal fluid, as described earlier, serve to support the notion that decompression after ACS may serve as a continued driver of multiple organ dysfunction. This data also suggests that prophylactic use of the open abdomen in certain high risk situations may affect the course of injury by preventing a second IR injury "hit." The interplay of IR, resuscitation, development of ACS, and reperfusion syndrome after decompression is demonstrated in Figure 2.

\section{Temporary abdominal coverage}

Having elucidated major pathophysiological processes that contribute to the development of ACS and dysfunction post-decompression, we now turn our focus to TAC. We will briefly review the types of TAC and the current clinical evidence supporting the use of various forms of TAC. We focus on studies evaluating ACS and related processes and evidence that support the notion that TAC may modulate systemic inflammatory processes.

\section{Choices for temporary abdominal closure}

Choice for TAC can broadly be divided into non negative pressure and negative pressure therapies.

Non negative pressure therapies The technique of planned re-operation for intra-abdominal pathology has been described since the 1980's. The technique was first widely adopted in the management of severe intraabdominal trauma [79]. One of the earliest methods of temporary closure was accomplished by using towel clips to close the skin. Although this was fast, cheap and minimized thermal and fluid losses, there were significant disadvantages, including the inability to visualize the wound, possible evisceration between clips, damage to skin, and a higher incidence of ACS due to decreased peritoneal reserve volume [80]. Increasing peritoneal cavity volume via the use of an artificial mesh is an option for TAC. There are several types of mesh that may be used, including polyglycolic acid (Vicryl ${ }^{\mathrm{TM}}$ ), polypropylene (Marlex ${ }^{\mathrm{TM}}$ ), or polytetrafluoroethylene (PTFE), and mesh closure techniques have been combined with zipper closure techniques to allow for serial examination of bowel [81-83]. Other options including other absorbable meshes (e.g., polyglycolic acid (Dexon)), biologic products, velcro-type closures (i.e., Wittmann Patch), and silastic sheeting have been described in the literature [84-88]. Mesh closure techniques have decreased in popularity secondary to adherence of bowel to mesh and potential for injury when taking down for re-exploration and potential for fascial trauma and necrosis (especially with repeated exploration and re-suturing) [81].

Another method of TAC is the Bogota bag, named by Mattox while observing surgery for trauma in Colombia. This method utilizes an intravenous fluid bag sewn to the skin to create a translucent silo to expand the effective volume of the abdominal cavity [89]. Advantages of this technique include speed, cost, and the ability to serially inspect abdominal contents. Initial series of TAC used the Bogota bag widely [90]; however, more recent literature indicates that this technique may associated with increased loss of fascial domain [80]. Modifications including sewing it to the fascia and progressive tightening of the bag with decreasing intra-abdominal edema have been described in an attempt to prevent retraction and increase likelihood for eventual fascial closure [91].

These techniques are associated with bowel fistula formation, retraction of the abdominal fascia, and intestinal adherence to the prosthesis. Lack of hermetic closure and efficient drainage can frequently cause profuse leakage of ascites, unpleasant nursing care and issues with fluid management.

Negative pressure therapies The first reported negative pressure assisted form of TAC was described by Schein et al and described for the use of abdominal sepsis. The "sandwich" technique utilized a piece of mesh sewn to the fascia with surgical drains overlaying and coverage with an adhesive dressing [92]. The vacuum pack method was a derivation of this technique. Utilizing commonly available materials (a perforated polyethylene sheet to protect peritoneal contents, surgical towels, silicone drains, and an adhesive plastic drape), an inexpensive negative pressure assisted method can be quickly fashioned. This technique was initially developed to prevent fascial trauma and to facilitate nursing care $[81,93,94]$. Various modifications of these techniques have been described [83,95-97].

Another popular negative pressure TAC device is the Vacuum Assisted Closure (VAC, Kinetic Concepts, Inc, San Antonio, TX) therapy system. The system requires the placement of a non-adherent perforated plastic barrier over the intra-abdominal viscera, followed by 


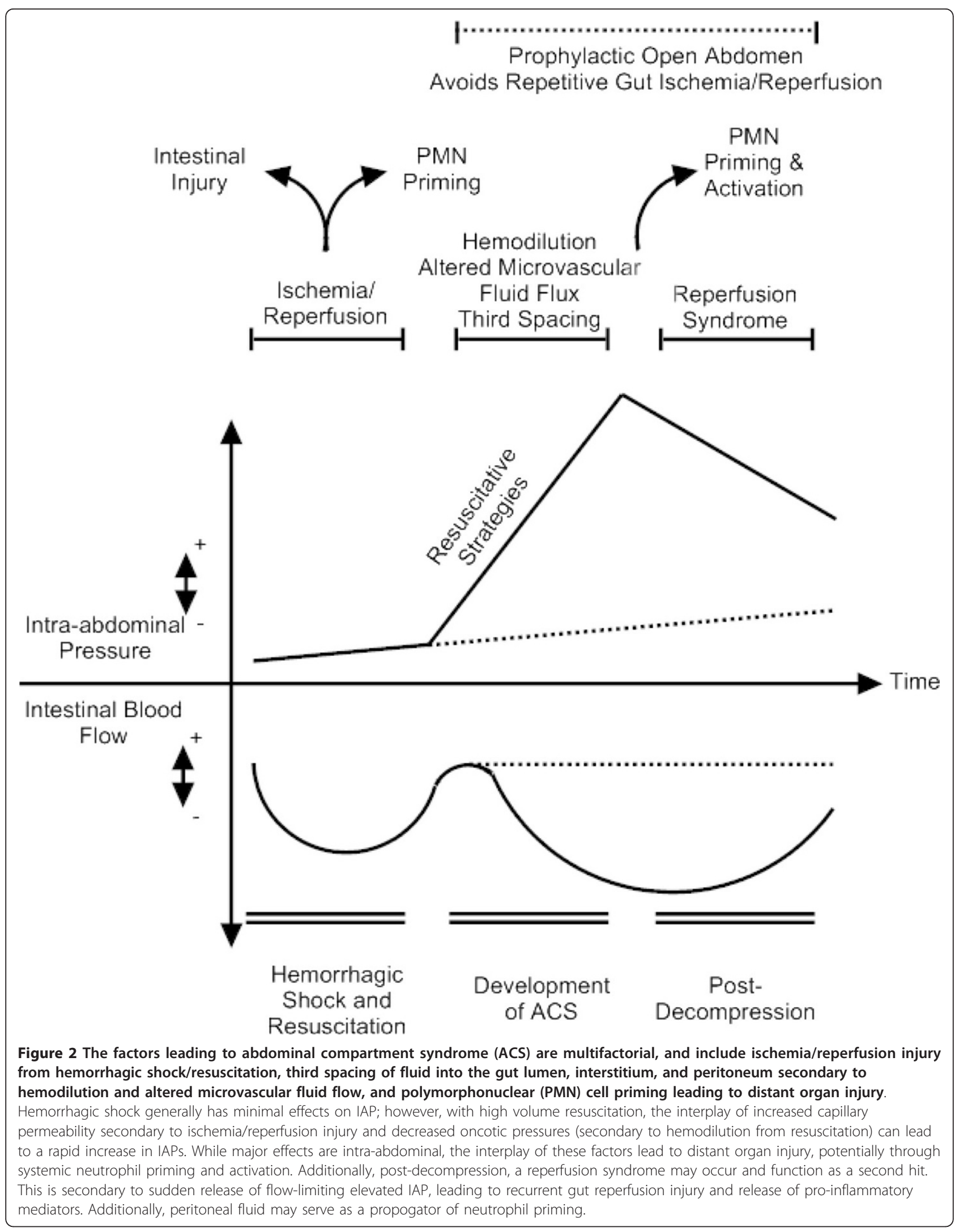


coverage with a polyurethane sponge and sealing with a plastic sheet. An aspiration system is connected to the sponge and a suction and negative pressure applied [98]. Many modifications of the VAC closure technique have been described $[99,100]$. In addition, new commercially available negative pressure dressings have recently been introduced (ABThera, Kinetic Concepts, Inc, San Antonio, TX; RENASYS Open Abdomen Solution, Smith and Nephew, St. Petersburg, FL)

\section{Evidence for temporary abdominal closure techniques}

Although there are a number of individual series describing individual institution experiences with varying forms of TAC, the focus of this review will be on series comparing differing forms of $\mathrm{TAC}$ to move towards an evidence based paradigm for choice of TACs in differing clinical situations. There are no prospective, randomized trials demonstrating superiority of any particular TAC technique.

Fascial closure There are few randomized trials comparing differing forms of TAC and eventual outcome with regards to fascial closure. Bee et al. conducted a randomized trial comparing VAC therapy to polyglactin mesh and demonstrated that no significant difference in delayed primary fascial closure rates, fistula formation ( $21 \%$ versus $5 \%$, VAC versus polyglactin mesh, respectively), or intra-abdominal abscess formation. It is important to note that the overall rate of fascial closure (approximately 30\%) is low when compared to other series, and may have been secondary to the patient population at the institution [101]. A recent meta-analysis evaluating negative pressure therapy (VAC, vacuum pack), Whitman patch, mesh closures (including mesh, zipper, and silo), skin closure, and retention sutures demonstrated that the Whitman patch, VAC therapy, and use of retention sutures led to the highest rates of delayed fascial closure [89].

Abdominal compartment syndrome in the open abdomen As indicated earlier, the fluidity of indications for the open abdomen, especially in the setting of abdominal trauma and risk factors known to harbor an increased risk of IAH, has led to significant pre-emptive use of TAC in an attempt to prevent development of ACS. Despite this, there is an entity that deserves attention; namely development of ACS in the open abdomen. Although there is scant literature on this topic, currently published evidence suggests that vacuum assisted TAC may harbor an increased risk of recurrent IAH and development of recurrent ACS. Gracias et al. published a series of development of ACS in the open abdomen and reported 5 cases - in all cases, ACS developed within 12 hours post-operatively and the vacuum pack dressing was utilized as TAC [32]. Two recent laboratory papers also suggest that negative pressure therapy decreases abdominal wall compliance and may harbor a theoretical increased risk of IAH [102,103]. It is important to note that in the Gracias series, 15 other patients were treated with the vacuum pack dressing without development of ACS and that there are currently no published prospective studies evaluating the effect of early application of vacuum assisted therapies in the setting of decompression from ACS.

Mortality and outcome - clinical studies A recent meta-analysis of series of differing TAC techniques demonstrated that VAC therapy and the Whitman patch were associated with the lowest mortality rates [89]. Series comparing outcome between TAC are almost universally retrospective. VAC therapy has been associated with improved early control of intra-abdominal pressure and normalization of lactate, faster time to fascial closure and ventilator weaning, and decreased intensive care unit and hospital length of stay when compared to Bogota bag closure for decompression from ACS. It is important to note in this series, although the study of patients treated with VAC was prospective, the control group was a retrospectively evaluated cohort at the beginning timepoint of the study. Although this study provides evidence that VAC therapy may have a global protective effect, other advancements in therapy and resuscitation practices over time may have accounted for the improved outcomes [104].

Laboratory data Although the majority of surveyed trauma surgeons used negative pressure assisted TAC [105], there are no prospective randomized trials demonstrating superiority in the setting of decompression from ACS. A careful examination of current laboratory data is therefore imperative. We reviewed earlier that recurrent ACS in the open abdomen was associated in one series with use of the vacuum pack technique. Additionally, Benninger et al. demonstrated that negative pressure therapy was associated with the lowest abdominal volume reserve capacity (i.e., lower volume of fluid resulted in a greater increase in IAP) in in-vitro and in-vivo models. The authors theorized that, in the setting of decompression from ACS, these therapies may place one at a higher risk for recurrent IAH $[102,103]$. These data mandate further study into the safety of negative pressure therapy in the immediate post-decompression period.

There are few pre-clinical studies evaluating negative pressure therapy in relevant large animal models. Kubiak et al. recently compared VAC therapy with negative pressure turned on to VAC therapy with negative pressure off in a large animal model of multiple organ dysfunction driven by gut IR and intra-abdominal sepsis. Notable findings included decreased mortality in the negative pressure group along with significant amelioration of lung injury. In addition, decreased systemic 
concentrations of pro-inflammatory cytokines were noted [106] In a clinically severe large animal model of non-infectious ACS, Shah et al. recently demonstrated that immediate post-decompression application of negative pressure therapy as compared to Bogota bag closure was associated with no increase in recurrent IAH or worsened outcomes with regards to physiological variables, organ edema, and organ histology. Given the small sample sizes, no conclusions could be made regarding survival. Negative pressure therapy was associated with reductions in central venous and mesenteric venous pressures which over time, may be associated with more favorable fluid flux profiles and augmented resolution of intestinal edema $[66,107,108]$. These data demonstrate that negative pressure therapy appears safe in the immediate post-decompression period from ACS and may be associated with improved outcomes/organ injury parameters.

\section{Conclusions/future study}

The literature on ACS and management of the open abdomen clearly demonstrate that prevention is the best cure. The consequences of managing an open abdomen are extensive; the entirely new surgical subspecialty of complex abdominal wall reconstruction has emerged to deal with some of these issues. Recent studies have indicated that damage control laparotomy and the use of TAC is, in some cases, overutilized [109]. Increased recognition of the causative factors and modifications in resuscitation strategies are serving to decrease the incidence of ACS, need for decompressive laparotomy, and consequent need for the open abdomen and TAC. We emphasize the point that prevention of the open abdomen represents a far superior strategy for patient management than any form of TAC for an open abdomen

There is a lack of randomized clinical trials evaluating the effects of a variety of TAC choices in the post decompression period from ACS. Recent laboratory data, however, suggest that negative pressure therapy may be associated with a global protective effect. Potential mechanisms of benefit are currently not well understood, however recent data on the pro-inflammatory nature of peritoneal fluid in infectious and non-infectious states and the role of mesenteric derived lymph in the systemic inflammatory process offer a basis for future study.

It is well documented that peritoneal fluid can be reabsorbed into the systemic circulation, primarily via lymphatic conduits $[64,110]$. Given this data and evidence that peritoneal fluid is pro-inflammatory by representing a potential primer for naïve neutrophils, a potential mechanism for systemic effects of peritoneal fluid can be proposed, either as an initiator (i.e., intraabdominal sepsis) or propagator of systemic inflammation. Abdominal cavity lymph has been widely studied as a mediator of distant lung injury. Laboratory studies have demonstrated that thoracic duct lymphatic diversion ameliorates lung injury in the setting of gut IR [111]. Part of the composition of thoracic duct derived lymph is reabsorbed peritoneal fluid. Given data demonstrating that negative pressure therapy ameliorates lung injury, peritoneal fluid may increase the pro-inflammatory characteristics of lymph given its major route of uptake being diaphragmatic and peritoneal cavity based lymphatic channels [106]. One potential explanation for these observations is that augmented removal of peritoneal fluid decreases the pro-inflammatory characteristics of abdominal-activity derived lymph resulting in decreased lung injury. Further study is necessary to confirm the hypothesis that negative pressure therapy may be a method to decrease the pro-inflammatory nature of abdominal cavity derived lymph.

While the preponderance of data does not provide definitive guidelines for the management of the open abdomen post-decompression from ACS, there is a growing volume of literature that suggests that the intra-abdominal cavity may be a way to modulate outcome. Preliminary data suggests that negative pressure therapy may be associated with a global protective effect and this may be based via an effect on peritoneal fluid. Further elucidation of this mechanism may allow for improved patient outcomes by appropriate choice of TAC.

\section{Abbreviations \\ TAC: emporary abdominal closure; IAH: intra-abdominal hypertension; IAP: intra-abdominal pressure; ACS: abdominal compartment syndrome; IR: ischemia/reperfusion; PLA 2: phospholipase A2; PAF: platelet activating factor; IL: interleukin; TNF: tumor necrosis factor; G-CSF: granulocyte colony stimulating factor; ICAM: intracellular adhesion molecule; STAT: signal transduction and activation of transcription; PTFE: polytetrafluoroethylene; VAC: vacuum assisted closure.}

\section{Acknowledgements}

Sources of Support

NIH Grants T32 GM 0879201 and RO1 HL 092916; Children's Memorial Hermann Hospital Foundation; Texas Higher Education Coordination Board.

\section{Author details}

'Department of Pediatric Surgery, University of Texas Medical School at Houston, Houston, Texas, USA. ${ }^{2}$ Department of Surgery, University of Texas Medical School at Houston, Houston, Texas, USA. ${ }^{3}$ Michael E. DeBakey Institute for Comparative Cardiovascular Science and Biomedical Devices, Texas A \& M University, College Station, Texas, USA. ${ }^{4}$ Department of Pediatric Surgery, University of Texas Medical School at Houston, 6431 Fannin Street, MSB 5.236, Houston, TX 77030, USA.

\section{Authors' contributions}

All authors participated in the conception, design, acquisition, analysis and interpretation of data, and drafting and critically revising the manuscript. All of the authors have approved the final submission of this manuscript.

Competing interests

Dr. Cox has received past research funding from Kinetic Concepts, Inc. 
Received: 21 November 2011 Accepted: 3 April 2012

Published: 3 April 2012

\section{References}

1. Schecter WP, Ivatury RR, Rotondo MF, Hirshberg A: Open abdomen after trauma and abdominal sepsis: a strategy for management. J Am Coll Surg 2006, 203:390-396.

2. Ivatury RR: Update on open abdomen management: achievements and challenges. World J Surg 2009, 33:1150-1153.

3. Balogh Z, McKinley BA, Cox CS Jr, Allen SJ, Cocanour CS, Kozar RA, Moore EE, Miller IC, Weisbrodt NW, Moore FA: Abdominal compartment syndrome: the cause or effect of postinjury multiple organ failure. Shock 2003, 20:483-492.

4. Malbrain ML, Cheatham ML, Kirkpatrick A, Sugrue M, Parr M, De Waele J, Balogh Z, Leppaniemi A, Olvera C, Ivatury R, et al: Results from the International Conference of Experts on Intra-abdominal Hypertension and Abdominal Compartment Syndrome. I. Definitions. Intensive Care Med 2006, 32:1722-1732.

5. Cheatham ML, Malbrain ML, Kirkpatrick A, Sugrue M, Parr M, De Waele J, Balogh Z, Leppaniemi A, Olvera C, Ivatury R, et al: Results from the International Conference of Experts on Intra-abdominal Hypertension and Abdominal Compartment Syndrome. II. Recommendations. Intensive Care Med 2007, 33:951-962

6. Balogh ZJ, van Wessem K, Yoshino O, Moore FA: Postinjury abdominal compartment syndrome: are we winning the battle? World J Surg 2009, 33:1134-1141.

7. Carter EA, Tompkins RG, Yarmush ML, Walker WA, Burke JF: Redistribution of blood flow after thermal injury and hemorrhagic shock. J Appl Physiol 1988, 65:1782-1788.

8. Scannell G, Clark L, Waxman K: Regional flow during experimental hemorrhage and crystalloid resuscitation: persistence of low flow to the splanchnic organs. Resuscitation 1992, 23:217-225.

9. Malbrain ML, De Laet I: AIDS is coming to your ICU: be prepared for acute bowel injury and acute intestinal distress syndrome. Intensive Care Med 2008, 34:1565-1569.

10. Otamiri T, Tagesson C: Role of phospholipase A2 and oxygenated free radicals in mucosal damage after small intestinal ischemia and reperfusion. Am J Surg 1989, 157:562-565, discussion 566.

11. Szabo A, Boros M, Kaszaki J, Nagy S: The role of mast cells in mucosal permeability changes during ischemia-reperfusion injury of the small intestine. Shock 1997, 8:284-291.

12. Sun Z, Wang $X$, Deng $X$, Lasson A, Wallen $R$, Hallberg E, Andersson R: The influence of intestinal ischemia and reperfusion on bidirectional intestinal barrier permeability, cellular membrane integrity, proteinase inhibitors, and cell death in rats. Shock 1998, 10:203-212.

13. Sun Z, Wang $X$, Lasson A, Borjesson A, Leveau P, Haraldsen P, Andersson R: Roles of platelet-activating factor, interleukin-1 beta and interleukin- 6 in intestinal barrier dysfunction induced by mesenteric arterial ischemia and reperfusion. J Surg Res 1999, 87:90-100.

14. Sun Z, Lasson A, Olanders K, Deng X, Andersson R: Gut barrier permeability, reticuloendothelial system function and protease inhibitor levels following intestinal ischaemia and reperfusion-effects of pretreatment with N-acetyl-L-cysteine and indomethacin. Dig Liver Dis 2002, 34:560-569.

15. Oktar BK, Gulpinar MA, Bozkurt A, Ghandour S, Cetinel S, Moini $\mathrm{H}$ Yegen BC, Bilsel S, Granger DN, Kurtel H: Endothelin receptor blockers reduce I/R-induced intestinal mucosal injury: role of blood flow. Am J Physiol Gastrointest Liver Physiol 2002, 282:G647-655.

16. Caty MG, Guice KS, Oldham KT, Remick DG, Kunkel SI: Evidence for tumor necrosis factor-induced pulmonary microvascular injury after intestinal ischemia-reperfusion injury. Ann Surg 1990, 212:694-700.

17. Wyble CW, Desai TR, Clark ET, Hynes KL, Gewertz BL: Physiologic concentrations of TNFalpha and IL-1 beta released from reperfused human intestine upregulate E-selectin and ICAM-1. J Surg Res 1996, 63:333-338.

18. Soares AL, Coelho FR, Guabiraba R, Kamal M, Vargaftig BB, Li L, Li J, Tavaresde-Lima W, Ryffel B: Tumor necrosis factor is not associated with intestinal ischemia/reperfusion-induced lung inflammation. Shock 34:306-313.
19. Yang YJ, Chen SH, Ge XR: Role of interleukin-18 in the development of acute pulmonary injury induced by intestinal ischemia/reperfusion and its possible mechanism. J Gastroenterol Hepatol 2007, 22:253-260.

20. Ishii H, Ishibashi M, Takayama M, Nishida T, Yoshida M: The role of cytokine-induced neutrophil chemoattractant-1 in neutrophil-mediated remote lung injury after intestinal ischaemia/reperfusion in rats. Respirology 2000, 5:325-331.

21. Carter MB, Wilson MA, Wead WB, Garrison RN: Platelet-activating factor mediates pulmonary macromolecular leak following intestinal ischemiareperfusion. J Surg Res 1996, 60:403-408.

22. Koike K, Moore EE, Moore FA, Kim FJ, Carl VS, Banerjee A: Gut phospholipase A2 mediates neutrophil priming and lung injury after mesenteric ischemia-reperfusion. Am J Physiol 1995, 268:G397-403.

23. Victoni T, Coelho FR, Soares AL, de Freitas A, Secher T, Guabiraba R, Erard F, de Oliveira-Filho RM, Vargaftig BB, Lauvaux G, et al: Local and remote tissue injury upon intestinal ischemia and reperfusion depends on the TLR/MyD88 signaling pathway. Med Microbiol Immunol 199:35-42.

24. Moraes LB, Murakami AH, Fontes B, Poggetti RS, van Rooijen N, Younes RN, Heimbecker AM, Birolini D: Gut ischemia/reperfusion induced acute lung injury is an alveolar macrophage dependent event. J Trauma 2008, 64:1196-1200, discussion 1200-1191

25. Uchida K, Mishima S, Ohta S, Yukioka T: Inhibition of inducible nitric oxide synthase ameliorates lung injury in rats after gut ischemia-reperfusion. $J$ Trauma 2007, 63:603-607.

26. Tian XF, Yao JH, Li YH, Zhang XS, Feng BA, Yang CM, Zheng SS: Effect of nuclear factor kappa $B$ on intercellular adhesion molecule-1 expression and neutrophil infiltration in lung injury induced by intestinal ischemia/ reperfusion in rats. World I Gastroenterol 2006, 12:388-392.

27. Wada K, Montalto MC, Stahl GL: Inhibition of complement C5 reduces local and remote organ injury after intestinal ischemia/reperfusion in the rat. Gastroenterology 2001, 120:126-133.

28. Mitsuoka H, Unno N, Sakurai T, Kaneko H, Suzuki S, Konno H, Terakawa S, Nakamura S: Pathophysiological role of endothelins in pulmonary microcirculatory disorders due to intestinal ischemia and reperfusion. $J$ Surg Res 1999, 87:143-151.

29. Hierholzer C, Kalff JC, Audolfsson G, Billiar TR, Tweardy DJ, Bauer Af: Molecular and functional contractile sequelae of rat intestinal ischemia/ reperfusion injury. Transplantation 1999, 68:1244-1254.

30. Hassoun HT, Weisbrodt NW, Mercer DW, Kozar RA, Moody FG, Moore FA: Inducible nitric oxide synthase mediates gut ischemia/reperfusioninduced ileus only after severe insults. J Surg Res 2001, 97:150-154

31. Livingston EH, Passaro EP Jr: Postoperative ileus. Dig Dis Sci 1990, 35:121-132.

32. Gracias VH, Braslow B, Johnson J, Pryor J, Gupta R, Reilly P, Schwab CW: Abdominal compartment syndrome in the open abdomen. Arch Surg 2002, 137:1298-1300.

33. Madigan MC, Kemp CD, Johnson JC, Cotton BA: Secondary abdominal compartment syndrome after severe extremity injury: are early, aggressive fluid resuscitation strategies to blame? J Trauma 2008, 64:280-285.

34. O'Mara MS, Slater H, Goldfarb IW, Caushaj PF: A prospective, randomized evaluation of intra-abdominal pressures with crystalloid and colloid resuscitation in burn patients. J Trauma 2005, 58:1011-1018.

35. Rodas EB, Malhotra AK, Chhitwal R, Aboutanos MB, Duane TM, Ivatury RR: Hyperacute abdominal compartment syndrome: an unrecognized complication of massive intraoperative resuscitation for extra-abdominal injuries. Am Surg 2005, 71:977-981.

36. Balogh Z, McKinley BA, Cocanour CS, Kozar RA, Holcomb JB, Ware DN, Moore FA: Secondary abdominal compartment syndrome is an elusive early complication of traumatic shock resuscitation. Am J Surg 2002, 184:538-543, discussion 543-534.

37. Fleming A, Bishop M, Shoemaker W, Appel P, Sufficool W, Kuvhenguwha A, Kennedy F, Wo CJ: Prospective trial of supranormal values as goals of resuscitation in severe trauma. Arch Surg 1992, 127:1175-1179, discussion 1179-1181.

38. Bishop MH, Shoemaker WC, Appel PL, Wo CJ, Zwick C, Kram HB, Meade P, Kennedy F, Fleming AW: Relationship between supranormal circulatory values, time delays, and outcome in severely traumatized patients. Crit Care Med 1993, 21:56-63. 
39. Ivy ME, Atweh NA, Palmer J, Possenti PP, Pineau M, D'Aiuto M: Intraabdominal hypertension and abdominal compartment syndrome in burn patients. J Trauma 2000, 49:387-391.

40. Weinstein PD, Doerfler ME: Systemic complications of fluid resuscitation. Crit Care Clin 1992, 8:439-448.

41. Davis MJ, Gore RW: Capillary pressures in rat intestinal muscle and mucosal villi during venous pressure elevation. Am J Physiol 1985, 249: H174-187.

42. Staub NC, Taylor AE: Edema New York: Raven Press; 1984

43. Laine GA, Allen SJ, Katz J, Gabel JC, Drake RE: Outflow pressure reduces lymph flow rate from various tissues. Microvasc Res 1987, 33:135-142.

44. Stewart RH, Laine GA: Flow in lymphatic networks: interaction between hepatic and intestinal lymph vessels. Microcirculation 2001, 8:221-227.

45. Shah SK, Uray KS, Stewart RH, Laine GA, Cox CS Jr: Resuscitation-induced intestinal edema and related dysfunction: state of the science. J Surg Res 166:120-130.

46. Cox CS Jr, Radhakrishnan R, Villarrubia L, Xue H, Uray K, Gill BS, Stewart RH, Laine GA: Hypertonic saline modulation of intestinal tissue stress and fluid balance. Shock 2008, 29:598-602.

47. Moore-Olufemi SD, Xue H, Attuwaybi BO, Fischer U, Harari Y, Oliver DH, Weisbrodt N, Allen SJ, Moore FA, Stewart R, et al: Resuscitation-induced gut edema and intestinal dysfunction. J Trauma 2005, 58:264-270.

48. Drake RE, Teague RA, Gabel JC: Lymphatic drainage reduces intestinal edema and fluid loss. Lymphology 1998, 31:68-73.

49. Unthank $\mathrm{L}$, Bohlen HG: Lymphatic pathways and role of valves in lymph propulsion from small intestine. Am J Physiol 1988, 254:G389-398.

50. Moore-Olufemi SD, Xue H, Allen SJ, Moore FA, Stewart RH, Laine GA, Cox CS Jr: Effects of primary and secondary intra-abdominal hypertension on mesenteric lymph flow: implications for the abdominal compartment syndrome. Shock 2005, 23:571-575.

51. Upperman JS, Deitch EA, Guo W, Lu Q, Xu D: Post-hemorrhagic shock mesenteric lymph is cytotoxic to endothelial cells and activates neutrophils. Shock 1998, 10:407-414.

52. Zallen G, Moore EE, Tamura DY, Johnson JL, Biffl WL, Silliman CC: Hypertonic saline resuscitation abrogates neutrophil priming by mesenteric lymph. J Trauma 2000, 48:45-48.

53. Adams CA Jr, Sambol JT, Xu DZ, Lu Q, Granger DN, Deitch EA: Hemorrhagic shock induced up-regulation of P-selectin expression is mediated by factors in mesenteric lymph and blunted by mesenteric lymph duct interruption. J Trauma 2001, 51:625-631, discussion 631-622.

54. Adams JM, Hauser CJ, Adams CA Jr, Xu DZ, Livingston DH, Deitch EA: Entry of gut lymph into the circulation primes rat neutrophil respiratory burst in hemorrhagic shock. Crit Care Med 2001, 29:2194-2198.

55. Dayal SD, Hasko G, Lu Q, Xu DZ, Caruso JM, Sambol JT, Deitch EA: Trauma/ hemorrhagic shock mesenteric lymph upregulates adhesion molecule expression and IL-6 production in human umbilical vein endothelial cells. Shock 2002, 17:491-495.

56. Gonzalez RJ, Moore EE, Ciesla DJ, Nieto JR, Johnson JL, Silliman CC: Posthemorrhagic shock mesenteric lymph activates human pulmonary microvascular endothelium for in vitro neutrophil-mediated injury: the role of intercellular adhesion molecule-1. J Trauma 2003, 54:219-223.

57. Xu DZ, Lu Q, Adams CA, Issekutz AC, Deitch EA: Trauma-hemorrhagic shock-induced up-regulation of endothelial cell adhesion molecules is blunted by mesenteric lymph duct ligation. Crit Care Med 2004, 32:760-765.

58. Deitch EA, Shi HP, Feketeova E, Hauser CJ, Xu DZ: Hypertonic saline resuscitation limits neutrophil activation after trauma-hemorrhagic shock. Shock 2003, 19:328-333.

59. Jordan JR, Moore EE, Sarin EL, Damle SS, Kashuk SB, Silliman CC, Banerjee A: Arachidonic acid in postshock mesenteric lymph induces pulmonary synthesis of leukotriene B4. J Appl Physiol 2008, 104:1161-1166.

60. Kowal-Vern A, Ortegel J, Bourdon P, Chakrin A, Latenser BA, Kimball D, Casey LC: Elevated cytokine levels in peritoneal fluid from burned patients with intra-abdominal hypertension and abdominal compartment syndrome. Burns 2006, 32:563-569.

61. Sagara D, Unno N, Mitsuoka H, Yamamoto N, Ishimaru K, Konno H: Transerosaly leaked gut-derived fluid activates neutrophils via phospholipase-A2 during open abdomina (sp) aortic aneurysm repair. Shock 2009, 31:43
62. Martineau L, Shek PN: Peritoneal cytokine concentrations and survival outcome in an experimental bacterial infusion model of peritonitis. Crit Care Med 2000, 28:788-794.

63. Granger DN, Barrowman JA: Microcirculation of the alimentary tract I. Physiology of transcapillary fluid and solute exchange. Gastroenterology 1983, 84:846-868.

64. Tarpila E, Nystrom PO, Ihse I: The resorption of FITC-dextran 10,000 from the peritoneum in different modifications of bile-induced acute pancreatitis and in bacterial peritonitis. Int J Pancreatol 1991, 10:229-236.

65. Bokesch PM, Kapural MB, Mossad EB, Cavaglia M, Appachi E, DrummondWebb JJ, Mee RB: Do peritoneal catheters remove pro-inflammatory cytokines after cardiopulmonary bypass in neonates? Ann Thorac Surg 2000, 70:639-643.

66. Shah SK, Jimenez F, Walker PA, Aroom KR, Xue H, Feeley TD, Uray KS, Norbury KC, Stewart RH, Laine GA, Cox CS Jr: A novel mechanism for neutrophil priming in trauma: Potential role of peritoneal fluid. Surgery 2010, 148:263-270

67. Shah SK, Jimenez F, Walker PA, Xue H, Feeley TD, Uray KS, Norbury KC, Stewart RH, Laine GA, Cox CS Jr: Peritoneal fluid: a potential mechanism of systemic neutrophil priming in experimental intra-abdominal sepsis. Am J Surg 2011

68. Cheatham ML, Safcsak K: Percutaneous catheter decompression in the treatment of elevated intraabdominal pressure. Chest 140:1428-1435.

69. De Waele JJ, Hoste EA, Malbrain ML: Decompressive laparotomy for abdominal compartment syndrome-a critical analysis. Crit Care 2006, 10 R51

70. Morris JA Jr, Eddy VA, Blinman TA, Rutherford EJ, Sharp KW: The staged celiotomy for trauma. Issues in unpacking and reconstruction. Ann Surg 1993, 217:576-584, discussion 584-576.

71. Schachtrupp A, Wauters J, Wilmer A: What is the best animal model for ACS? Acta Clin Belg Suppl 2007, 225-232.

72. Diebel LN, Dulchavsky SA, Wilson RF: Effect of increased intra-abdominal pressure on mesenteric arterial and intestinal mucosal blood flow. $J$ Trauma 1992, 33:45-48, discussion 48-49.

73. Diebel LN, Dulchavsky SA, Brown WJ: Splanchnic ischemia and bacterial translocation in the abdominal compartment syndrome. J Trauma 1997 43:852-855.

74. Rezende-Neto JB, Moore EE, Melo de Andrade MV, Teixeira MM, Lisboa FA Arantes RM, de Souza DG, da Cunha-Melo JR: Systemic inflammatory response secondary to abdominal compartment syndrome: stage for multiple organ failure. J Trauma 2002, 53:1121-1128.

75. Oda J, Ivatury RR, Blocher CR, Malhotra AJ, Sugerman HJ: Amplified cytokine response and lung injury by sequential hemorrhagic shock and abdominal compartment syndrome in a laboratory model of ischemiareperfusion. J Trauma 2002, 52:625-631, discussion 632.

76. Simon RJ, Friedlander MH, Ivatury RR, DiRaimo R, Machiedo GW: Hemorrhage lowers the threshold for intra-abdominal hypertensioninduced pulmonary dysfunction. J Trauma 1997, 42:398-403, discussion 404-395.

77. Ihtiyar E, Fatih Yasar N, Erkasap N, Koken T, Tosun M, Oner S, Erkasap S: Effects of Doxycycline on Renal Ischemia Reperfusion Injury Induced by Abdominal Compartment Syndrome. J Surg Res 2009

78. Kacmaz A, Polat A, User Y, Tilki M, Ozkan S, Sener G: Octreotide improves reperfusion-induced oxidative injury in acute abdominal hypertension in rats. J Gastrointest Surg 2004, 8:113-119.

79. Hirshberg A, Wall MJ Jr, Mattox KL: Planned reoperation for trauma: a two year experience with 124 consecutive patients. J Trauma 1994, 37:365-369.

80. Rutherford EJ, Skeete DA, Brasel KJ: Management of the patient with an open abdomen: techniques in temporary and definitive closure. Curr Probl Surg 2004, 41:815-876.

81. Brock WB, Barker DE, Burns RP: Temporary closure of open abdominal wounds: the vacuum pack. Am Surg 1995, 61:30-35

82. Perez A, Hilvano S: Abdominal zippers for temporary abdominal closure in planned relaparotomies for peripancreatic sepsis: experience in a developing country. J Hepatobiliary Pancreat Surg 2001, 8:449-452.

83. Navsaria PH, Bunting M, Omoshoro-Jones J, Nicol AJ, Kahn D: Temporary closure of open abdominal wounds by the modified sandwich-vacuum pack technique. Br J Surg 2003, 90:718-722 
84. Wittmann DH, Aprahamian C, Bergstein JM, Edmiston CE, Frantzides CT, Quebbeman EJ, Condon RE: A burr-like device to facilitate temporary abdominal closure in planned multiple laparotomies. Eur J Surg 1993, 159:75-79.

85. Ercan F, Korkmaz A, Aras N: The zipper-mesh method for treating delayed generalized peritonitis. Surg Today 1993, 23:205-214

86. Cuesta MA, Doblas M, Castaneda L, Bengoechea E: Sequential abdominal reexploration with the zipper technique. World J Surg 1991, 15:74-80.

87. Hadeed JG, Staman GW, Sariol HS, Kumar S, Ross SE: Delayed primary closure in damage control laparotomy: the value of the Wittmann patch. Am Surg 2007, 73:10-12.

88. Howdieshell TR, Yeh KA, Hawkins ML, Cue Jl: Temporary abdominal wall closure in trauma patients: indications, technique, and results. World J Surg 1995, 19:154-158.

89. Boele van Hensbroek P, Wind J, Dijkgraaf MG, Busch OR, Carel Goslings J: Temporary closure of the open abdomen: a systematic review on delayed primary fascial closure in patients with an open abdomen. World J Surg 2009, 33:199-207.

90. Hirshberg A, Mattox KL: Planned reoperation for severe trauma. Ann Surg 1995, 222:3-8.

91. Myers JA, Latenser BA: Nonoperative progressive "Bogota bag" closure after abdominal decompression. Am Surg 2002, 68:1029-1030.

92. Schein M: Planned reoperations and open management in critical intraabdominal infections: prospective experience in 52 cases. World J Surg 1991, 15:537-545.

93. Barker DE, Kaufman HJ, Smith LA, Ciraulo DL, Richart CL, Burns RP: Vacuum pack technique of temporary abdominal closure: a 7-year experience with 112 patients. J Trauma 2000, 48:201-206, discussion 206-207.

94. Smith LA, Barker DE, Chase CW, Somberg LB, Brock WB, Burns RP: Vacuum pack technique of temporary abdominal closure: a four-year experience. Am Surg 1997, 63:1102-1107, discussion 1107-1108.

95. Wilde JM, Loudon MA: Modified Opsite sandwich for temporary abdominal closure: a non-traumatic experience. Ann R Coll Surg Engl 2007, 89:57-61.

96. Chin PK, Dunn J: Temporary abdominal wall closure using a sterile drape technique. Ann R Coll Surg Engl 2006, 88:319-320.

97. Keramati M, Srivastava A, Sakabu S, Rumbolo P, Smock M, Pollack J, Troop B: The Wittmann Patch $s$ a temporary abdominal closure device after decompressive celiotomy for abdominal compartment syndrome following burn. Burns 2008, 34:493-497.

98. Garner GB, Ware DN, Cocanour CS, Duke JH, McKinley BA, Kozar RA, Moore FA: Vacuum-assisted wound closure provides early fascial reapproximation in trauma patients with open abdomens. Am J Surg 2001, 182:630-638.

99. Cothren CC, Moore EE, Johnson JL, Moore JB, Burch JM: One hundred percent fascial approximation with sequential abdominal closure of the open abdomen. Am J Surg 2006, 192:238-242.

100. Petersson U, Acosta S, Bjorck M: Vacuum-assisted wound closure and mesh-mediated fascial traction-a novel technique for late closure of the open abdomen. World J Surg 2007, 31:2133-2137.

101. Bee TK, Croce MA, Magnotti LJ, Zarzaur BL, Maish GO, Minard G, Schroeppel TJ, Fabian TC: Temporary abdominal closure techniques: a prospective randomized trial comparing polyglactin 910 mesh and vacuum-assisted closure. J Trauma 2008, 65:337-342, discussion 342-334.

102. Benninger $E$, Labler $L$, Seifert $B$, Trentz O, Menger MD, Meier C: In vitro comparison of intra-abdominal hypertension development after different temporary abdominal closure techniques. J Surg Res 2008, 144:102-106.

103. Benninger E, Laschke MW, Cardell M, Keel M, Seifert B, Trentz O, Menger MD, Meier $C$ : Intra-abdominal pressure development after different temporary abdominal closure techniques in a porcine model. $J$ Trauma 2009, 66:1118-1124.

104. Batacchi S, Matano S, Nella A, Zagli G, Bonizzoli M, Pasquini A, Anichini V, Tucci V, Manca G, Ban K, et al: Vacuum-assisted closure device enhances recovery of critically ill patients following emergency surgical procedures. Crit Care 2009, 13:R194.

105. MacLean AA, O'Keeffe T, Augenstein J: Management strategies for the open abdomen: survey of the American Association for the Surgery of Trauma membership. Acta Chir Belg 2008, 108:212-218.

106. Kubiak BD, Albert SP, Gatto LA, Snyder KP, Maier KG, Vieau CJ, Roy S, Nieman GF: Peritoneal negative pressure therapy prevents multiple organ injury in a chronic porcine sepsis and ischemia/reperfusion model. Shock 2010, 34:525-534.

107. Shah S, Jimenez F, Walker P, Xue H, Feeley T, Uray K, Norbury K, Stewart R, Laine G, Cox C: Evaluating the effects of immediate application of negative pressure therapy after decompression from abdominal compartment syndrome in an experimental porcine model. European Journal of Trauma and Emergency Surgery 2011.

108. Radhakrishnan RS, Shah SK, Lance SH, Radhakrishnan HR, Xue H, Radhakrishnan GL, Ramaswamy US, Walker PA, Uray KS, Laine GA, et al: Hypertonic saline alters hydraulic conductivity and up-regulates mucosal/submucosal aquaporin 4 in resuscitation-induced intestinal edema. Crit Care Med 2009, 37:2946-2952.

109. Hatch QM, Osterhout LM, Podbielski J, Kozar RA, Wade CE, Holcomb JB, Cotton BA: Impact of closure at the first take back: complication burden and potential overutilization of damage control laparotomy. J Trauma 71:1503-1511.

110. Ishimaru K, Mitsuoka H, Unno N, Inuzuka K, Nakamura S, SchmidSchonbein GW: Pancreatic proteases and inflammatory mediators in peritoneal fluid during splanchnic arterial occlusion and reperfusion. Shock 2004, 22:467-471.

111. Liu C, Wu Q, Li Q, Liu D, Su H, Shen N, Tai M, Lv Y: Mesenteric lymphatic ducts ligation decreases the degree of gut-induced lung injury in a portal vein occlusion and reperfusion canine model. J Surg Res 2009, 154:45-50.

doi:10.1186/1757-7241-20-25

Cite this article as: Shah et al:: Strategies for modulating the inflammatory response after decompression from abdominal compartment syndrome. Scandinavian Journal of Trauma, Resuscitation and Emergency Medicine 2012 20:25.

\section{Submit your next manuscript to BioMed Central and take full advantage of:}

- Convenient online submission

- Thorough peer review

- No space constraints or color figure charges

- Immediate publication on acceptance

- Inclusion in PubMed, CAS, Scopus and Google Scholar

- Research which is freely available for redistribution

Submit your manuscript at www.biomedcentral.com/submit
Biomed Central 